\title{
Reflexões sobre o Brasil e os desafios Pan-Amazônicos
}

Reflections on Brazil and the Pan-Amazonian challenges

PIO PENNA FILHO*

Rev. Bras. Polít. Int. 56 (2): 94-111 [2013]

\section{Introdução}

Muitos são os desafios que se apresentam para o Brasil em termos amazônicos, tanto no plano doméstico como nos planos regional e internacional. No plano doméstico, de longa data se apresenta a questão da sua ocupação e integração ao restante do País, além da contenção do desmatamento descontrolado e da efetiva presença do Estado na região. No plano regional, o maior desafio é a integração com os países vizinhos, numa perspectiva Pan-Amazônica, além do controle dos ilícitos transfronteiriços, que incluem uma série de atividades ilegais que vão desde o tráfico de drogas ao contrabando e descaminho de diversos tipos de produtos. Já no plano internacional, há tempos paira no ar o receio da relativização da soberania brasileira sobre a Amazônia, um pensamento que vem atormentando principalmente os setores mais nacionalistas da sociedade brasileira.

A Pan-Amazônia, maior floresta tropical e bacia hidrográfica do mundo, conta com 7,8 milhões de quilômetros quadrados distribuídos entre 9 países, sendo um deles de fora do continente. ${ }^{1}$ Os números indicam que sua área equivale a $60 \%$ da superfície da América Latina e que o Brasil é o detentor da maior parte de todo esse fabuloso território, de sorte que o País possui $67,8 \%$ da área total. Para se ter uma ideia da relevância da dimensão territorial pertencente ao Brasil, basta dizer que em segundo lugar, em termos nacionais, vem o Peru, com uma área equivalente a 13\% do total da Floresta Amazônica, ficando, portanto, bem atrás do Brasil.

Alguns outros dados indicam a dimensão amazônica brasileira. Assim, a chamada Amazônia Legal detém 59\% do território brasileiro e possui $11.300 \mathrm{~km}$ de fronteiras com sete países vizinhos, quais sejam: Bolívia, Colômbia, Guiana, Guiana Francesa (França), Peru, Suriname e Venezuela (Tabela 1). São cerca de

* Pio Penna Filho é Professor Adjunto do Instituto de Relações Internacionais (IREL) da Universidade de Brasília (UnB), Brasília, Brasil (piopenna@gmail.com).

1 A área total da Pan-Amazônia varia de acordo com a fonte. Optamos, neste trabalho, pelos dados da Red Amazónica de Información Socioambiental Georreferenciada (RAISG). Os dados podem ser acessados no site $<$ http://raisg.socioambiental.org>. Acesso em 20 de março de 2013. 
$25.000 \mathrm{~km}$ de vias navegáveis dentro de nove estados da República Federativa do Brasil, ou seja, os estados do Acre, Amapá, Amazonas, Maranhão, Mato Grosso, Pará, Rondônia, Roraima e grande parte do Tocantins estão, em alguma medida, vinculados a sua vasta e importante rede hidrográfica. ${ }^{2}$

Tabela 1. Extensão total da região amazônica em comparação com o território continental de cada país.

\begin{tabular}{|l|c|c|c|}
\hline \multicolumn{1}{|c|}{ País } & Superfície total $\left(\mathbf{k m}^{2}\right)$ & Superfície amazônica $\left(\mathbf{k m}^{2}\right)$ & $\%$ Amazônia \\
\hline Brasil & 8.514 .876 & 5.006 .316 & 58,8 \\
Bolívia & 1.098 .581 & 475.278 & 43,3 \\
Colômbia & 1.138 .910 & 483.119 & 42,4 \\
Equador & 248.406 & 116.604 & 46,9 \\
Guiana & 214.969 & 214.969 & 100,0 \\
Guiana Francesa & 86.504 & 86.504 & 100,0 \\
Peru & 1.285 .215 & 782.820 & 60,9 \\
Suriname & 163.820 & 163.820 & 100,0 \\
Venezuela & 916.445 & 453.915 & 49,5 \\
\hline
\end{tabular}

Fonte: RAISG (2009). Disponível em: <http://raisg.socioambiental.org>. Acesso em 20 de março de 2013.

Apenas no lado brasileiro, esse imenso território possui uma população de pouco mais de 25 milhôes de habitantes, abriga $56 \%$ da população indígena do País, conta com vastas áreas esparsamente ocupadas e nas quais a maior parte de seus habitantes se concentra nas cidades de Manaus e Belém, as capitais dos estados do Amazonas e do Pará, os dois maiores da região. ${ }^{3} \mathrm{O}$ Estado do Amazonas é o maior do País em área territorial e equivale aos territórios somados de França, Espanha, Suécia e Grécia, o que nos dá uma amostra de sua grandiosidade. Por outro lado, sua densidade demográfica é muito baixa e sua população vive, predominantemente, em áreas urbanas, espalhadas de forma muito desigual, entre os 62 municípios do Estado. ${ }^{4}$

2 Segundo o IPEA, "o conceito de Amazônia Legal foi instituído em 1953 e seus limites territoriais decorrem da necessidade de planejar o desenvolvimento econômico da região e, por isso, não se resumem ao ecossistema de selva úmida, que ocupa $49 \%$ do território nacional e se estende também pelo território de oito países vizinhos. Os limites da Amazônia Legal foram alterados várias vezes em consequência de mudanças na divisão política do país. O Plano Amazônia Sustentável (PAS), lançado em maio deste ano [2011] pelo governo federal, considera integralmente o Estado do Maranhão como parte da Amazônia Brasileira". "O que é? Amazônia Legal”. Disponível em: $<$ http://www.ipea.gov.br/desafios/index.php?option=com_content\&id=2154:catid=28\&Itemid=23>. Acesso dia 15 de março de 2013.

3 Dados do Censo de 2010 disponíveis no site do IBGE. A respeito, ver: <http://www.ibge.gov.br/home/ estatistica/populacao/censo2010/default.shtm>. Acesso em 15 de março de 2013.

4 A população do Estado, de acordo com o Censo de 2010 do Instituto Brasileiro de Geografia e Estatística (IBGE), é de 3.483.985 habitantes, dos quais 2.755 .490 vivem em áreas urbanas e apenas 728.495 em áreas rurais. A capital, Manaus, abriga 1.802 .525 habitantes. Existem ainda 65 diferentes grupos indígenas, o que representa a maior população de índios do Brasil, com um total de 168.680. Dados disponíveis em <http://www. amazonas.am.gov.br/o-amazonas/dados/>. Acesso em 18 de março de 2013. 
À parte algumas outras cidades de médio e pequeno porte, existem também os habitantes que vivem nas cercanias dos rios, população conhecida como "ribeirinha" ou "povos da floresta". As áreas ocupadas pelos ribeirinhos são quase totalmente desprovidas de infraestrutura básica e quase totalmente dependentes de transportes fluviais, com pouca ou nenhuma assistência do Estado, o que torna a vida nessas regiōes ainda mais difícil. Sua economia é, de certa forma, rudimentar e poucas são as perspectivas de um desenvolvimento mais autônomo e rentável.

A Pan-Amazônia possui, ademais, enormes riquezas, muitas ainda não exploradas ou pouco exploradas. A floresta detém o maior número de espécies vivas do planeta, a maior reserva de água doce, madeiras nobres, vastas jazidas minerais (muitas sequer mapeadas), e grande potencial para geração de energia hidrelétrica, dentre outros recursos. Destaque-se, além do que foi elencado, todo o potencial genético contido em seu ecossistema e a imensurável riqueza traduzida na diversidade de sua população, ainda mais com grupos indígenas que sequer travaram contato com o chamado homem "branco". Toda essa riqueza e diversidade estão espalhadas pela vasta área da região amazônica entre os seus condôminos, não se restringindo a este ou àquele país em particular.

\section{A Pan-Amazônia - desenvolvimento, integração, preservacionismo e interesses estrangeiros}

Rica em recursos naturais e em biodiversidade e componente inseparável do estado brasileiro, a Pan-Amazônia precisa ser melhor estudada e compreendida para que possamos nos preparar para os desafios do presente e do futuro. Não é de hoje que outros países e interesses se debruçam sobre a região amazônica, seja em nome de uma pretensa preservação ambiental, seja embalado por inconfessos interesses materiais relacionados ao acesso e controle de suas riquezas.

O Brasil, como detentor da maior parte do território amazônico, tem não só o direito ao exercício da soberania sobre a região, mas também o dever de proteger o seu ecossistema e as populações nacionais que lá habitam. Não pode, portanto, o Brasil abrir mão, abandonar ou deixar qualquer vazio de poder naquela importante e estratégica região, sob pena de enfrentar forças capazes de impor visōes incompatíveis com a perspectiva da soberania nacional.

A Amazônia, todavia, não se encerra no Brasil. Nesse sentido, faz-se necessário um olhar atento para o entorno regional, sobretudo para os países vizinhos que com o Brasil compartilham e conformam a Pan-Amazônia. Uma análise mais detalhada da bacia amazônica demonstra justamente o caráter regional da mesma, ou seja, deve-se observar a interdependência e transnacionalização do ecossistema, das riquezas e oportunidades, mas também dos seus problemas e desafios.

Entendida como um sistema complexo que seria melhor compreendido se não fosse compartimentado, manter a soberania, o desenvolvimento e a capacidade de 
preservação da Amazônia não são desafios apenas para o Brasil, senão que envolve todos os outros países limítrofes. A Amazônia conforma um sistema regional que compartilha problemas e desafios semelhantes e demanda uma abordagem também compartilhada, embora o Brasil se coloque, quase que de forma natural, como o país mais capacitado para liderar esse verdadeiro complexo regional. Nesse caso, a ideia de liderança não implica necessariamente assumir uma capacidade de influenciar politicamente os outros Estados, embora isso seja desejável a partir de uma perspectiva brasileira.

Infelizmente, o espírito de liderança é falho no Brasil. Há uma grande expectativa entre os países da América do Sul para com o Brasil que, via de regra, é frustrada quando o País é chamado a liderar politicamente a região. Por um lado, a diplomacia brasileira age com uma excessiva cautela e se intimida frente a muitos desafios sul-americanos, ocorrendo, em certas ocasiōes, de o País se tornar inoperante e se deixar levar pelos acontecimentos. Por outro, há de se reconhecer os esforços que vêm sendo realizados, mesmo que ainda de forma tímida e difusa, para ampliar o grau de integração física da região, haja vista que a ausência de infraestrutura física básica é um grande complicador e um dos elementos que mais dificultam uma ação conjunta dos países amazônicos. Assim, não basta a existência de planos, alguns dos quais mirabolantes, que sempre jogam para o futuro a integração dos países da região.

É compreensível que a criação de uma infraestrutura física seja um objetivo de longo prazo, sobretudo pela dificuldade em integrar e conectar a região como um todo, tendo em vista suas características naturais. Aliás, se dependesse dos discursos oficiais que enfatizam a necessidade dessa integração, ela já estaria concluída há muito tempo; infelizmente não é o que se verifica na prática.

Essa não é uma questão recente. Historicamente, os países amazônicos se desenvolveram voltados praticamente de costas para a Pan-Amazônia. Enquanto no Brasil os principais núcleos urbanos e planos desenvolvimentistas se concentraram na região Sudeste do País e foram projetados em direção ao litoral, nos países vizinhos o processo não foi muito diferente. Assim, a região amazônica foi ficando relativamente relegada para o futuro. Sua ocupação foi, portanto, postergada, e só passou a receber mais atenção a partir da década de 1970 e, mesmo assim, de forma muito incipiente e desordenada, o que gerou um quadro quase caótico de ocupação em várias partes do seu território, pelo menos no caso brasileiro.

No plano internacional extrarregional, observa-se um comportamento de cobiça sobre a Amazônia que remonta ao século 19. Mas foi apenas no final do século 20 que esse interesse começou a se tornar mais efetivo e intenso. Ele ganhou fôlego em torno de um discurso ecológico e ambiental, e, a partir de então, se formou uma enorme pressão sobre o Brasil que ora se amplia, ora se ameniza; esse discurso, de toda forma, está consolidado na agenda internacional. Trata-se de um tema que dificilmente deixará de ser um dos mais destacados no plano internacional, 
principalmente pelo arrojado e internacionalizado movimento ambientalista que age em escala global e está disseminado entre os países mais desenvolvidos e nas principais organizaçôes internacionais do mundo atual.

Os desafios e as ameaças à Amazônia são múltiplos. Podemos encontrá-los nos níveis doméstico, regional e internacional. No nível doméstico, o maior desafio - e que interage ativamente com os demais - diz respeito à integração efetiva e mais harmoniosamente possível da região com o resto do Brasil; fenômeno semelhante ocorre entre os demais países da Pan-Amazônia. Isso se dá porque os planos até agora implementados com vistas à plena integração da Amazônia às outras regiōes foram apenas parcialmente executados em alguns países e, em outros, sequer foram considerados ou se encontram em estágio muito incipiente. Assim, a realidade atual é que existem vastas áreas onde não se percebe a presença do Estado, o que gera a sensação de um perigoso vazio de poder, geralmente ocupado por atividades e interesses associados a ilicitudes de diversas naturezas e com grandes impactos ambientais, o que aliás ajuda a consolidar e, de certa maneira, legitimar o discurso internacional de proteção ambiental.

Não é uma tarefa simples a integração das zonas amazônicas aos núcleos mais centrais dos Estados da bacia. Em primeiro lugar porque, historicamente, como observado anteriormente, todos os países se projetaram em direções opostas à bacia ou, quando diferente, apenas mantiveram uma presença mais restrita na região. Em segundo lugar, há de se destacar a dificuldade de implementar projetos de ocupação e desenvolvimento na região tendo em vista as características naturais da bacia. É, de fato, uma tarefa complexa, com os recursos disponíveis nos países da região, manter uma presença estável do Estado que seja capaz de dotar os territórios de infraestrutura condizente com as demandas sociais, tanto dos empreendedores quanto da sociedade em geral.

Hoje, por exemplo, há de se notar a insegurança jurídica e humana provocada pela mudança de enfoque para com a região. Se, na década de 1970, por exemplo, a ideia predominante era a de desmatar grandes extensões de florestas para ocupar as terras com atividades produtivas, como se verificou sobretudo nos atuais estados do Mato Grosso e de Rondônia (mas não apenas neles), com iniciativas tanto públicas como privadas de ocupação da terra, atualmente a tendência é valorizar a preservação ambiental e reconhecer os direitos dos povos indígenas, o que provoca conflitos fundiários (com grandes, médios e pequenos proprietários, além de posseiros e até mesmo grileiros) e com grupos específicos, como com os garimpeiros, e diminui o interesse de muitos empreendedores na região.

A questão indígena, pelo menos no caso brasileiro, é um dos grandes desafios para a integração e exploração dos recursos de grandes áreas da Amazônia na perspectiva do desenvolvimentismo. Abundam exemplos de conflitos que travam ou dificultam obras importantes para o desenvolvimento do País, como é o caso da construção de hidrelétricas na região. 
No plano regional, os problemas se multiplicam. Os vizinhos amazônicos do Brasil possuem uma presença ainda menor do Estado nas partes mais profundas de suas respectivas zonas amazônicas, reproduzindo os problemas afetos à ausência ou pouca presença do Estado verificados no Brasil. Há casos mais graves, como o da Colômbia, no qual atividades guerrilheiras, agora associadas ao narcotráfico, promovem insegurança que facilmente transborda para além das fronteiras daquele país, gerando mais insegurança na região.

A precária coordenação entre os Estados da Pan-Amazônia para promoção de açôes conjuntas objetivando uma abordagem regional e sistêmica voltada para encontrar soluções conjuntas para os problemas comuns é outra debilidade importante. Apesar da existência de uma Organização Internacional - Organização do Tratado de Cooperação Amazônica (OTCA) - criada justamente para essa finalidade, os seus resultados são ainda muito precários.

Já no plano internacional, não é de hoje que existe uma intensa atividade com relação aos assuntos amazônicos, em muitos casos com interesses políticos e econômicos que contrariam os interesses nacionais. Além da retórica ecológica de muitos ambientalistas, assistimos a declaraçôes de Chefes de Estado, ou de ex-Chefes de Estado, de outros países que enfatizam a necessidade de "proteção" internacional da floresta. Na mesma linha, é observável também a ação de centenas de Organizações Não Governamentais (ONGs) que utilizam tanto a retórica ambiental quanto a indigenista para promover interesses contrários aos nacionais dos países amazônicos, tais quais percebidos por seus diferentes governantes.

É até curioso notar que a abordagem brasileira se distancia da visão dos países do "Norte", principalmente porque o Brasil identifica a necessidade premente do desenvolvimento sustentável da região como forma de melhorar a qualidade de vida dos seus habitantes, ao mesmo tempo em que tal desenvolvimento possibilitaria uma conexão mais articulada com o restante do País e com os Estados vizinhos. O mesmo vale, grosso modo, para os vizinhos.

Uma das grandes questôes que se coloca em termos amazônicos diz respeito a como compatibilizar a exploração dos recursos encontrados na Amazônia com a preservação ambiental e com os direitos das populações nativas e não nativas que há muito tempo habitam a região. A expansão do agronegócio, a exploração de gás e petróleo, as atividades de extração de madeira, ouro e outros minerais e a construção de hidrelétricas realizadas até o presente momento já demonstraram quão agressivas são essas atividades para um ecossistema relativamente frágil, assim como também são perturbadoras para as vidas das pessoas que moram na vasta zona amazônica.

Trata-se, na verdade, de um paradoxo, porque não há como desenvolver e integrar as respectivas regiōes amazônicas ao restante dos países que a compõem sem implementar projetos de desenvolvimento que dependem de fortes inversóes dos Estados nacionais e que inevitavelmente provocam efeitos colaterais sobre o meio ambiente. Seria uma grande ilusão pensar exclusivamente em termos de proteção 
ambiental sem considerar as necessidades humanas e dos países que conformam a Pan-Amazônia. No fundo, não há muita diferença em termos de países, uma vez que as necessidades de praticamente todos os Estados amazônicos convergem para esse paradoxo entre os ideais "preservacionistas" e os "desenvolvimentistas". O que muda, sobretudo em decorrência de características particulares de cada Estado amazônico, é a necessidade e intensidade da sua projeção em direção ao interior da Amazônia.

De toda forma, é possível, até certo ponto, compatibilizar desenvolvimento com preservação, no sentido da sustentabilidade do desenvolvimento. Nesse caso em específico, a presença do Estado em toda a região Pan-Amazônica se torna condição sine qua non para que algum grau de sustentabilidade seja alcançado no processo de desenvolvimento da região.

Sem uma ação decidida por parte dos Estados amazônicos, prevalecerão a exploração predatória dos recursos locais e a evasão de parte substancial desses recursos em direção a países de fora da região. Já existe, por exemplo, um intenso tráfico em torno das riquezas amazônicas realizado por meio da chamada "biopirataria", que contrabandeia diversas espécies da flora e da fauna regional, além de tentar se apropriar e monopolizar, por meio do registro de patentes, de conhecimentos e saberes das populações nativas da Amazônia. Conforme aponta o Ministério do Meio Ambiente do governo brasileiro,

Historicamente, o uso dos recursos e conhecimentos genéticos e dos conhecimentos tradicionais associados tem ocorrido de forma injusta. Os países de origem dos recursos genéticos e as comunidades indígenas e locais, detentoras de conhecimentos tradicionais associados, sequer têm sido consultados pelos que utilizam desses recursos para obter ganhos econômicos com produtos comerciais, quanto mais recebido qualquer tipo de benefício. Esta apropriação injusta, muitas vezes agravada pelo uso das patentes, corresponde a biopirataria, e tem ocorrido ao longo de toda a história do Brasil. (MMA 2013).

A questão da biopirataria é apenas um dos problemas enfrentados pelos países da Pan-Amazônia frente aos grandes interesses internacionais em torno dos recursos amazônicos. Existe um grande e promissor potencial em termos de biodiversidade que ainda é muito pouco conhecido e explorado, seja pelas populaçôes locais, seja pelos países detentores da soberania amazônica. Ilustra bem esse quadro a informação de que as populações indígenas empregam aproximadamente 1.300 diferentes plantas para fins medicinais, que possuem princípios ativos "característicos de antibióticos, narcóticos, anticoncepcionais, antidiarreicos, anticoagulantes, fungicidas, anestésicos, antiviróticos e relaxantes musculares". ${ }^{5}$ É de se imaginar a variedade de patentes no campo da saúde que

5 Sobre esses dados ver documento "O Lugar da Amazônia no Desenvolvimento do Brasil - Programa de Governo 2002 da Coligação Lula Presidente”, p. 6. Disponível em: <http://www.fpabramo.org.br/uploads/ olugardaamazonianodesenvolvimento.pdf $>$. Acesso em 16 de março de 2013. 
podem sair de tão vasto acervo que se encontra espalhado pela Pan-Amazônia. Mas as riquezas da biodiversidade não se restringem ao campo da saúde. Existe também um enorme potencial em termos alimentares e toda uma tradição "imaterial" que acaba chamando a atenção de muitos outros países e grupos para a Amazônia.

Ainda no campo da biopirataria, vale a pena uma referência ao fato de que tanto o Brasil como os demais países amazônicos encontram-se numa absurda situação de vulnerabilidade institucional e jurídica para combater essa modalidade de ilícito internacional, via de regra transformado em atos legais sob o abrigo da lei de patentes, por mais imoral que possa parecer. ${ }^{6}$ Com efeito, os países da Pan-Amazônia praticamente não avançaram na discussão do tema e parece que ainda se está muito longe de uma ação coordenada. No caso do Brasil, o país mais visado de todos, apesar da regulamentação por Medida Provisória (2186-16, de 2001), a biopirataria continua sendo praticada quase que livremente, uma vez que a regulamentação não conseguiu estancar esse processo e nem tampouco o Estado criou ou adequou órgãos de fiscalização que conseguissem imprimir um controle mais efetivo sobre a presença de atividades estrangeiras dedicadas à biopirataria.

Uma breve lista de patentes requeridas no exterior, por diversos países - quase todos desenvolvidos -, demonstra como é grande o interesse internacional pelos valiosos recursos da biodiversidade amazônica. Além disso, é preciso considerar que muitas plantas e material nativo já foram retirados do ecossistema original e são hoje cultivados em outras partes do mundo. Vale também lembrar o caso relativamente recente, que causou certa irritação e reação por parte do governo e da sociedade do Brasil, da tentativa de biopirataria "legal" levado a efeito pela multinacional japonesa Asahi Foods Co. Ltd, de Kyoto. Nesse episódio, o Escritório de Marcas do Japão (JPO) tentou o registro da marca comercial do cupuaçu que, caso tivesse sido bem-sucedido, daria à empresa Asahi, por meio de uma subsidiária criada justamente para essa finalidade, a "Cupuacu International", a patente para a produção industrial de um chocolate obtido com a utilização da semente da fruta. A iniciativa foi contestada pelo governo brasileiro e por ONGs e a pressão deu resultado, uma vez que o próprio Escritório de Marcas do Japão solicitou a retirada do pedido da marca por parte da empresa em 2004 . $^{7}$

6 Como destaca Flávia Piedade, um dos mais importantes acordos internacionais e consagrado na legislação internacional de proteção à propriedade intelectual, o Acordo sobre Aspectos dos Direitos de Propriedade Intelectual Relacionados ao Comércio - Agreement on Trade-Related Aspects of Intellectual Property Rights (TRIPS) -, referido mais comumente como Acordo TRIPS, é um instrumento que favorece ou contribui para a biopirataria, haja vista que em seu artigo 27.3(b), o acordo "autoriza os países membros do acordo a excluírem, em suas legislações nacionais, a concessão de patentes a plantas, animais e processos essencialmente biológicos para produção de plantas e animais, obrigando apenas à proteção por patentes microrganismos, processos não biológicos e microbiológicos”. Ver: PIEDADE, Flávia Lordello. Biopirataria e direito ambiental: estudo de caso do сириас̧u. Piracicaba: Escola Superior de Agricultura Luiz de Queiroz (USP), 2008, p. 10.

7 A esse respeito ver: HOMMA, Alfredo Kingo Oyama. Extrativismo, biodiversidade e biopirataria na Amazônia. Brasília: Embrapa Informação Tecnológica, 2008, p. 69. Ver também: "Símbolo da biopirataria, cupuaçu ganha status de fruta nacional do Brasil”. Folha de São Paulo, 21/05/2008. Disponível em: <http://www1.folha.uol. com.br/folha/ciencia/ult306u404005.shtml>. Acesso em 19 de março de 2013. 
Como dito, outros países da Pan-Amazônia sofrem ações e pressões semelhantes ao Brasil em termos de biopirataria, mas com um ingrediente a mais que aumenta o grau de preocupação. Nesse sentido, a assinatura de Tratados de Livre Comércio entre a Colômbia (segundo país do mundo com maior biodiversidade vegetal e maior número de plantas conhecidas) e os Estados Unidos e entre o Peru (classificado entre os dez países do mundo com maior biodiversidade) e os Estados Unidos abre uma enorme via de possibilidades para que a biopirataria seja executada praticamente de forma legal por parte dos Estados Unidos, sobretudo pelos interesses privados representados pelo governo norte-americano. Essa questão pode assumir um contorno ainda mais grave caso a Uniāo Europeia, que já está em processo de negociação de acordos de livre comércio com ambos, reivindique o mesmo tratamento dispensado aos Estados Unidos, ou seja, as mesmas vantagens em torno da aquisição e registro de material biológico coletado nesses países.

Alguns estudos críticos elaborados nos países vizinhos ressaltam que os norte-americanos têm utilizado os Tratados de Livre Comércio para defender seus interesses não apenas no campo comercial, mas também adicionam cláusulas ambientais e de propriedade intelectual que abrem possibilidades de acesso e apropriação de recursos da biodiversidade amazônica. Conforme um estudo colombiano,

En el marco del Tratado bilateral que pretende firmar ambos países, uno de los temas de mayor interés para Estados Unidos, es el capítulo ambiental y especialmente el tema de la biodiversidad y la aplicación de propiedad intelectual sobre toda la materia viva y conocimientos tradicionales. Para este país del Norte, la enorme riqueza que posee Colombia en biodiversidad y recursos genéticos potencialmente útiles para la industria biotecnológica, pone a estos recursos en el centro de la negociación, y desde el inicio se puso sobre la mesa la posición de Estados Unidos frente al tema. Un eje central del acuerdo firmado, es la creación de condiciones para las inversiones en absolutamente todos los sectores de la economía y de la sociedad. Para ello el gobierno se compromete a realizar las adecuaciones jurídicas necesarias para darles garantía de tratamiento nacional a los inversionistas. (Semillas 2008, 60).

A assinatura desses tratados tem se mostrado perigosa para uma abordagem que leve em conta os interesses das populaçôes locais e dos Estados da PanAmazônia. Ao assinarem acordos que permitem a apropriação privada por parte de empresas dos países desenvolvidos de recursos da Pan-Amazônia (Tabela 2), os governos da Colômbia e do Peru estão, ao mesmo tempo, passando por cima de suas respectivas sociedades e ajudando a desmontar o pouco que foi realizado pela Comunidade Andina de Nações (CAN) acerca dessa temática. 
Tabela 2. Patentes sobre produtos das plantas amazônicas requeridas em diversos países desenvolvidos

\begin{tabular}{l|c|l}
\hline \multicolumn{1}{|c|}{ Produto } & Número de patentes & \multicolumn{1}{c}{ Países } \\
\hline Castanha-do-pará & 73 & EUA \\
Andiroba & 2 & França, Japão, UE, EUA \\
Ayahuasca & 1 & EUA \\
Copaíba & 3 & França, EUA \\
Cunaniol & 2 & UE, EUA \\
Cupuaçu & 6 & Japão, Inglaterra, UE \\
Curare & 9 & Inglaterra, EUA \\
Espinheira Santa & 2 & Japão, UE \\
Jaborandi & 20 & Inglaterra, EUA, Canadá, Irlanda \\
Amapá-doce & 3 & Rússia, Coreia do Sul \\
Piquiá & 1 & Japão \\
Jambu & 4 & Japão \\
Sangue-de-drago & 7 & EUA, Inglaterra, Japão, UE \\
Tipir & 3 & Inglaterra, Canadá \\
Unha-de-gato & 6 & EUA, Polônia \\
Vacina do sapo & 10 & EUA, UE, Japão \\
\hline
\end{tabular}

Fonte: HOMMA, Alfredo Kingo Oyama. Extrativismo, biodiversidade e biopirataria na Amazônia. Brasília: Embrapa Informação Tecnológica, 2008.

A precariedade do controle dos órgãos responsáveis no Brasil se revela também por meio do impressionante e expressivo tráfico de animais silvestres, retirados principalmente da Amazônia. Segundo a Polícia Federal, essa atividade ilícita está entre as mais frequentes do mundo, perdendo apenas para o tráfico de armas, drogas e seres humanos. Assim, muitos animais são retirados da Amazônia e vendidos ilegalmente, tanto no Brasil quanto no exterior. O Instituto Brasileiro do Meio Ambiente e dos Recursos Naturais Renováveis (Ibama) apreendeu, apenas em 2009, mais de 31 mil animais silvestres retirados de seus habitats naturais e vendidos ilegalmente. Estima-se que cerca de $40 \%$ dos animais extraídos apenas da fauna brasileira seguem para o mercado internacional, principalmente para a Europa (Duarte 2010).

\section{Cenários da Pan-Amazônia}

Ao projetarmos os possíveis e mais prováveis cenários regionais para a PanAmazônia, há de se considerar algumas importantes variáveis, como a evolução dos quadros políticos nacionais e suas interações no plano regional, considerandose principalmente o comportamento dos atores amazônicos mais proeminentes (Brasil, Colômbia, Venezuela e Peru) e da visibilidade e atenção que a região pode 
despertar perante a comunidade internacional, sobretudo pelo agravamento ou não da questão ambiental e do aquecimento global, que são considerados como os temas que têm mais chances de colocar em evidência a Pan-Amazônia no âmbito internacional.

Parte-se, nesta parte do artigo, de pressupostos nacionais e regionais convergindo e interagindo para ampliar, reduzir ou manter o status quo da Pan-Amazônia, em parte permeados por problemas comuns, como os ilícitos transnacionais, a necessidade de cooperação como países condôminos de um sistema interdependente e as perspectivas diante dos interesses de poderosos países de fora da região com relação aos temas amazônicos.

\section{Cenário regional}

O contexto amazônico mudou muito desde a década de 1970, quando a Amazônia se torna um tema de grande destaque na agenda política brasileira, principalmente pela preocupação despertada para sua integração mais efetiva ao território nacional, o que levou a medidas como abertura de estradas, expansão da fronteira agrícola e implementação de polos de desenvolvimento econômico. Começou, assim, a surgir uma região muito diferente da anterior, tanto em termos de desenvolvimento econômico e de ocupação humana do seu território. Todavia, esse processo de transformação da paisagem amazônica teve e tem resultados negativos, como grandes impactos ambientais e humanos (principalmente para suas populaçôes autóctones), além de uma maior visibilidade internacional, acompanhada de perto pela intensificação de um discurso ambientalista questionador da validade da tese da soberania nacional sobre o ecossistema amazônico.

No plano regional, considerando como marco o período iniciado na década de 1970, houve, assim como no Brasil - porém em menor escala -, uma gradativa descoberta do potencial amazônico pelos países vizinhos, mesmo considerando que nenhum deles tenha projetado planos mais ousados para a integração da área amazônica aos seus núcleos socioeconômicos principais. De toda forma, ocorreu um movimento crescente no sentido de ampliar a presença do Estado na Amazônia, mesmo que em áreas pontuais, com o duplo discurso de exploração dos recursos naturais existentes e preservação ambiental.

\section{A questão colombiana e a Pan-Amazônia}

Um caso muito particular no âmbito regional e que possui significado especial para a Pan-Amazônia é o da Colômbia. Com efeito, a perspectiva colombiana se difere das demais pela presença perturbadora para toda a região de um grupo de guerrilha ainda atuante e que mescla questôes ideológicas com o problema do narcotráfico. Isso é importante porque vários episódios demonstram o efeito de 
spillover das questôes colombianas para os seus vizinhos. Um dos efeitos colaterais desse problema, por exemplo, foi a implementação do Plano Colômbia, que trouxe de forma mais intensa para a região a presença militar dos Estados Unidos, o que contraria frontalmente os interesses brasileiros e de vários outros países amazônicos (principalmente Venezuela, Equador e Bolívia), haja vista a preocupação nacional com qualquer modalidade de ingerência de grandes potências na América do Sul e, em especial, na Amazônia.

Assim, a persistência das atividades das Forças Armadas Revolucionárias da Colômbia (FARC) e sua associação com o narcotráfico impõem desafios que não se restringem à perspectiva colombiana. É certo que a guerrilha se encontra atualmente em estado de relativa fragilidade, mas a incapacidade das forças regulares colombianas, mesmo associadas à ajuda militar norte-americana, em impor uma derrota decisiva para as FARC é um sintoma de que o problema persistirá e que sua solução provavelmente deverá conter um elemento essencialmente político. Nesse sentido, caso a Colômbia persista na sua política de tentar resolver a questão das FARC por meio essencialmente da força em estreita aliança com os Estados Unidos, o país continuará destoando dos demais e mantendo sua especificidade.

É preciso considerar, entretanto, os interesses colombianos e compreender que a aproximação do país com os Estados Unidos seguiu uma lógica própria que pode, inclusive, ser associada à manutenção da ordem interna e do controle do Estado sobre o seu território. A Colômbia foi, com efeito, o país da América do Sul que mais sofreu com as atividades do narcotráfico e das guerrilhas. Com dificuldades internas para manter a situação sob controle, tanto pela ação das guerrilhas como pela existência de poderosos cartéis do narcotráfico - que provocaram uma violenta disputa intra-cartéis e também uma forte contestação à autoridade do Estado -, e pressionado externamente sobretudo pelos negócios ilícitos envolvendo as drogas, havia pouca escolha para as lideranças colombianas. Assim, a parceria com os Estados Unidos foi, de certa forma, providencial para que o país não entrasse na lista dos estados falidos no final dos anos 1990.

A atuação das FARC e a resistência da maior parte dos países sul-americanos em identificarem oficialmente o grupo como tendo "evoluído" para uma narcoguerrilha, criou uma situação complicada na relação entre os países vizinhos e a Colômbia. Além disso, a presença norte-americana na Amazônia colombiana e as consequências de algumas açôes planejadas em conjunto entre o governo da Colômbia e os norte-americanos criaram ainda mais dissensos políticos na região. É o caso, por exemplo, do emprego do agente químico glifosato, aspergido nas plantações de coca na Colômbia mas que rapidamente contaminou territórios e mananciais além das fronteiras colombianas.

Outro exemplo ainda mais grave, pelo menos do ponto de vista político, foi o desrespeito à soberania territorial dos vizinhos. Esse foi o caso, registrado de maneira mais contundente, da ação militar levada a efeito pelo Exército colombiano contra 
um acampamento militar das FARC em solo equatoriano. ${ }^{8}$ Embora não tenha sido a única operação militar fora da Colômbia, foi a mais grave pela sua dimensão e pela captura de informaçóes importantes que estavam em poder de um alto líder da guerrilha que foi morto na operação. Além disso, existe ainda a desconfiança da maior parte dos países sul-americanos com a livre utilização de bases localizadas em território colombiano pelas Forças Armadas dos Estados Unidos.

Por tudo isso e pelo destacado crescimento de sua economia, a Colômbia, portanto, é um país-chave para considerarmos qualquer cenário mais positivo (ou negativo) e que contemple avanços (ou retrocessos) no processo de integração e articulação política no espaço amazônico. Nesse sentido, e considerando o caso especial do país, tudo dependerá do fim do conflito FARC versus governo colombiano, seja por uma vitória militar - caso menos provável -, seja por um acordo que coloque fim à guerra. Nesse cenário, a normalização política do país numa situação pós-conflito tem tudo para afastar da região a presença direta dos Estados Unidos e pavimentar o caminho para o melhor entendimento entre a Colômbia e todos os seus vizinhos.

É de se ressaltar que, corroborando esse pensamento, há na Colômbia a ideia de que o diálogo e a parceria com o Brasil são importantes para ambos os países em diversas matérias, da segurança e cooperação regional à consolidação da democracia e do Estado de direito. Em recente obra publicada no país, os principais temas das relaçôes bilaterais foram abordados justamente na perspectiva da aproximação entre os dois países, contemplando inclusive a inserção regional e as abordagens de ambos em direção à construção de uma identidade sul-americana mais consistente (Buelvas, Jost, e Flemes 2012). De fato, a recente discussão em torno de uma maior aproximação entre Colômbia e Brasil é algo ainda em fase inicial, haja vista que até bem pouco tempo o parceiro identificado como estratégico por importantes intelectuais brasileiros - e, por que não dizer, até mesmo pelo próprio governo brasileiro - era a Venezuela, e não a Colômbia. Podemos estar, assim, diante de uma inflexão da política externa brasileira no que diz respeito às suas opções na região amazônica.

Essa projeção muda caso o conflito colombiano persista ou mesmo se agrave. Nesse outro cenário, tudo indica que a Colômbia continuará sendo um país destoante dos demais por suas relaçôes especiais com os Estados Unidos e pelo problema da guerrilha associado à questão do narcotráfico, de impacto ainda maior para a região e para o mundo. Se, simultaneamente, persistirem governos

8 Esse episódio ocorreu em $1^{\circ}$ de março de 2008, quando um acampamento das FARC foi atacado e destruído pelo exército colombiano. No ataque, o exército da Colômbia utilizou o mesmo tipo de bomba que os norteamericanos usaram no Iraque, em 1991, o que demonstra a aproximação militar entre o país e os Estados Unidos. Aliás, as FARC afirmam que, na verdade, a operação militar teria sido conduzida pelos norte-americanos, e não pelos colombianos. Entretanto, não existe nenhum consenso a esse respeito. Sobre o assunto ver: "Bombas usadas contra as Farc no Equador são as mesmas que as da guerra do Golfo". Disponível em: <http://g1.globo.com/ Noticias/Mundo/0,,MUL359223-5602,00.html>. Acesso em 23 de março de 2013. 
mais à esquerda em países vizinhos como Venezuela, Bolívia e Equador, o quadro se agravará ainda mais.

É importante que se diga que o narcotráfico não é um problema exclusivamente colombiano, uma vez que atinge a totalidade dos países da Pan-Amazônia. A questão é que a Colômbia é o país que detém o papel de maior produtor mundial e que conta em seu território com vastas áreas de plantio de coca. Além disso, é preciso considerar o envolvimento transnacional da cadeia produtiva da cocaína que está muito presente no país. Assim, os produtores e traficantes colombianos e seus associados estão diretamente ligados a outros crimes transnacionais, como lavagem de dinheiro, contrabando de precursores utilizados na produção da cocaína, tráfico de armas e conexões com outras organizações criminosas espalhadas não apenas pelo América do Sul, haja vista que possuem conexões em outros continentes.

Por tudo isso e muito mais há de se considerar a necessidade de o Brasil buscar uma aproximação maior com a Colômbia. Além de compartilharmos uma grande área de fronteira, compartilhamos também muitos problemas em comum. Se a Colômbia é o maior produtor mundial de cocaína, o Brasil é um dos maiores consumidores da droga, além de grande corredor de exportação. O crime organizado que atua no Brasil possui conhecidas conexôes com os narcotraficantes colombianos e, em grande medida, a alta taxa de violência urbana verificada no Brasil decorre do tráfico de drogas, o que é um exemplo a mais a demonstrar as interações, mesmo que indiretas, entre os dois países. Está claro, após décadas de crescimento da violência no Brasil, que o País não conseguirá eliminá-la ou controlá-la apenas por meio da repressão.

\section{Impactos ambientais e intervencionismo internacional}

Qualquer projeção que diga respeito à Pan-Amazônia deve levar em consideração a questão ambiental e suas repercussōes internacionais. A exploração dos recursos naturais e a ocupação do solo na região têm aumentado em praticamente todos os países amazônicos e os impactos ambientais decorrentes desse processo são inevitáveis. No atual contexto e no horizonte de curto e médio prazos a principal questão não diz mais respeito ao dilema de explorar ou não os recursos amazônicos, mas sim de como explorar a região de forma sustentável e, preferencialmente, com autonomia por parte dos países detentores de territórios amazônicos.

A autonomia para a exploração da Amazônia se encontra em risco permanente, assim como a própria soberania dos Estados amazônicos sobre a Pan-Amazônia. Como destaca Rosineide Bentes, "entre 1989 e 2002, a Amazônia se tornou o primeiro, e até agora único, objeto da intervenção direta do ambientalismo internacional" (Bentes 2005, 225). Embora não se possa descartar a existência de um pensamento genuinamente preservacionista por trás do ativismo ambientalista, 
não se deve descartar, de forma alguma, os interesses econômicos e políticos de grandes potências ou de instituições e atores internacionais que muitas vezes se utilizam desse discurso para embasar de maneira sub-reptícia os seus objetivos e interesses.

Mas mesmo diante da pressão internacional em torno do ativismo ambientalista, os países da Pan-Amazônia, no geral, estão passando por um processo de tomada de consciência de que é preciso integrar os seus núcleos mais ativos às áreas da floresta. Como observado anteriormente, até bem pouco tempo atrás o Brasil era praticamente o único país amazônico que planejou e executou uma política de ocupação e exploração da região, tendo aumentado consideravelmente a presença do Estado na chamada Amazônia Legal. Naturalmente que essa ocupação e exploração se fez e ainda se faz de forma um tanto precária, mas esse é um diferencial que deve ser registrado. Contudo, outros países começaram também a, digamos, "descobrir" vocaçôes amazônicas.

Já existem investimentos em diversos setores sendo executados em países como Colômbia, Peru e Bolívia, além, naturalmente, do próprio Brasil. Praticamente todas as inversōes na Pan-Amazônia levam a algum grau de impacto ambiental, haja vista que empreendimentos de setores como a agropecuária, a mineração, o cultivo de ilícitos (a ampliação das áreas de cultivo de coca se dá, via de regra, às expensas de novos desmatamentos, principalmente na Amazônia colombiana, peruana e boliviana), a prospecção de petróleo e gás, a construção de hidrelétricas, a abertura de estradas, e melhorias nas vias fluviais, entre outros, não são realizáveis sem afetar o meio ambiente.

Em termos políticos, perante os países desenvolvidos do Hemisfério Norte, custam caro para a imagem dos Estados da Pan-Amazônia os impactos ambientais provocados pelo aumento do nível das atividades econômicas na região. Como os países amazônicos não estão dispostos a manter a floresta intacta e nem tampouco a restringir a atividade econômica a processos de pouco impacto ambiental, haja vista a necessidade de melhorar a qualidade de vida das pessoas que habitam a região e de utilizar esses recursos para o desenvolvimento dos seus países, é de se esperar que a pressão internacional não irá desaparecer ou mesmo diminuir. Nesse caso, o cenário mais provável é o aumento do ativismo dos movimentos ambientalistas, que podem inclusive passar a contar com maior empenho de determinados governos do Norte, principalmente de países europeus e dos Estados Unidos. Além disso, não é difícil imaginar o envolvimento de organizações internacionais com o tema, haja vista que elas são igualmente muito suscetíveis ao discurso ambientalista.

O modo mais eficaz de se contrapor a esse ativismo internacional, que cada vez mais possui um indisfarçável caráter ideológico e que se desenvolve por meio de determinados países e ONGs e alcança Organizações Internacionais, é o de aumentar a presença do Estado na Pan-Amazônia em diferentes frentes.

Não é possível para um único país, como o Brasil, fazer frente sozinho e de forma plenamente autônoma, a esse crescente ativismo. A ideia de aumentar a 
presença do Estado na Pan-Amazônia é entendida aqui não apenas com a execução de projetos desenvolvimentistas ou por meio apenas do aumento da presença militar. É importante que haja uma concertação política regional que passa pelo fortalecimento da OTCA e pelo estreitamento dos laços políticos dos países vizinhos, independente de condicionantes ideológicas.

\section{Considerações finais}

A Pan-Amazônia é uma região estratégica para o Brasil e para os países que a compõem. Além dos diversos recursos naturais encontrados em seu ecossistema, existe em torno da Pan-Amazônia toda uma perspectiva estratégica, política e econômica que interessa diretamente aos países condôminos. Ela é um ponto vital para qualquer programa de integração sul-americano, se constituindo em elemento essencial para a integração continental em sua dimensão mais ampla, isso sem contar que os impactos ambientais que atingem a zona amazônica acabam repercutindo também em outras áreas do continente sul-americano. Além disso, o discurso do internacionalismo ambientalista que proliferou nas últimas décadas chamou ainda mais a atenção internacional sobre a Pan-Amazônia, elevando consideravelmente os riscos da internacionalização do seu território, o que afeta de maneira mais intensa, entre todos os países da bacia, o Brasil.

As questôes envolvendo a Pan-Amazônia são complexas e o seu caráter regional sugere que abordagens igualmente regionais poderiam, afinal, promover sinergias entre os países mais diretamente relacionados à região para o encaminhamento tanto de programas de cooperação, em seus múltiplos níveis, como de questões políticas. Todavia, é preciso considerar os interesses individuais dos atores envolvidos, o que muitas vezes impõe severas restrições para ações conjuntas. Talvez a prova mais concreta e contundente de tal assertiva seja o lento ritmo de integração e cooperação alcançado por meio do Tratado de Cooperação Amazônica e, depois, da OTCA. Assim, é realmente um exercício de idealismo imaginar que a Pan-Amazônia possa, num cenário de curto e médio prazos, estar plenamente integrada ou mesmo em estágio mais avançado em seu processo de integração.

Tudo isso, contudo, não remove os graves problemas e desafios da PanAmazônia. A integração física da região é um imperativo imediato, embora o seu ritmo real seja lastimável. A presença do Estado em toda a Pan-Amazônia ainda deixa muito a desejar, abrindo caminho ou facilitando a ação de diversos ilícitos transnacionais com grandes impactos societários, sobretudo pela ação do narcotráfico. Essa mesma ausência possibilita que interesses privados - nacionais e internacionais - incrementem num nível incompatível com a sustentabilidade diversos programas de exploração econômica na região, causando grandes impactos ambientais e chamando a atenção de atores externos, normalmente capitaneados pelo discurso do internacionalismo ambiental, para a região. 
Assim, em toda a Pan-Amazônia, o maior desafio é ampliar a presença e coordenação dos Estados condôminos para que, guiados pela responsabilidade ambiental, possam manter as respectivas soberanias nacionais e integrar, da maneira mais harmoniosa possível, os seus territórios amazônicos aos respectivos núcleos territoriais.

\section{Referências bibliográficas}

BENTES, Rosineide. "A intervenção do ambientalismo internacional na Amazônia". Estudos Avançados, vol. 19, n. 54, maio/agosto 2005. São Paulo: USP/IEA, 2005.

BRASIL. Ministério do Meio Ambiente. Biopirataria. MMA. Brasília, 2013. Disponível em: <http://www.mma.gov.br/patrimonio-genetico/biopirataria>. Acesso em 20 de março de 2013.

BUELVAS, Eduardo Pastrana; JOST, Stefan; FLEMES, Daniel (Eds). Colombia y Brasil: socios estratégicos en la construcción de Sudamérica? Bogotá: Editorial Pontificia Universidad Javeriana: Fundación Konrad Adenauer: German Institute of Global and Area Studies (GIGA): Universidad San Buenaventura, 2012.

DUARTE, Nathália. (2010) Saiba qual é a rota do tráfico de animais silvestres no Brasil. Site G1 (Globo.com) Brasil, 07/10/2010. Disponível em: <http://g1.globo.com/brasil/noticia/2010/10/ saiba-qual-e-rota-do-trafico-de-animais-silvestres-no-brasil.html>. Acesso dia 19 de março de 2013.

HOMMA, Alfredo Kingo Oyama. Extrativismo, biodiversidade e biopirataria na Amazônia. Brasília: Embrapa Informação Tecnológica, 2008.

PIEDADE, Flávia Lordello. Biopirataria e direito ambiental: estudo de caso do cupuaçu. Piracicaba: Escola Superior de Agricultura Luiz de Queiroz -USP, 2008.

SEMILLAS. Biopiratería - Una amenaza a los territorios colectivos de Colombia. Estrategias y acciones desde la sociedad para enfrentarla. Bogotá: ARFO, 2008.

Recebido em 28 de maio de 2013 Aprovado em 20 de novembro de 2013

\section{Resumo}

O objetivo deste artigo é o estudo das interações regionais e desafios internacionais sobre a Pan-Amazônia, uma região considerada estratégica para o Brasil. Sua importância se verifica em múltiplos campos, com destaque para o ambiental e para o econômico - aliás, duas perspectivas que, mesmo não sendo excludentes, revelam-se de difícil compatibilização, sobretudo quando o assunto converge para a exploração dos diversos recursos naturais existentes na Pan-Amazônia e para o exercício da soberania nacional sobre os seus territórios. Mas o escopo temático do artigo é ainda mais amplo, haja vista que um dos principais objetivos do estudo é tentar articular as questões ambientais e econômicas conexas à Pan-Amazônia com aspectos políticos relacionados à segurança regional e nacional em torno da hileia, partindo do pressuposto que estamos diante de um quadro complexo apreendido em sua dimensão regional. Por fim, realiza-se um exercício sobre prováveis cenários envolvendo a Pan-Amazônia, tanto na perspectiva regional como na internacional.

Palavras-chave: ambientalismo; narcotráfico; Pan-Amazônia. 


\begin{abstract}
The aim of this paper is to study the interactions of regional and international pressure on the Pan-Amazon, a region considered strategic for Brazil. Its importance lies in multiple fields, with emphasis on the environment and the economy. Two perspectives, although not incompatible, reveal themselves difficult to harmonize, especially when it converges to the exploitation of natural resources in the Pan-Amazon and the exercise of national sovereignty over their territories. But the thematic scope of the article is even wider, since one of the main objectives of the study is to try to articulate the environmental and economic issues related to the Pan-Amazon with policy issues related to regional security and national levels around the Brazilian Amazon, assuming that the issue is even more complex when contemplated in its regional dimension. Finally, we carried out an exercise on scenarios involving the Pan-Amazon at both the regional and the international levels.
\end{abstract}

Keywords: environmentalism; illegal drug trade; Pan-Amazon. 